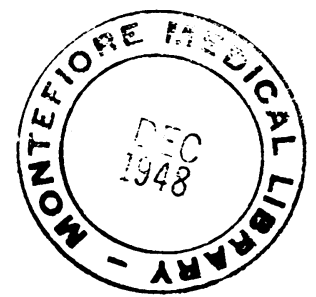

\title{
NEUROVASCULAR RELATIONS AND ANOMALIES AT THE BASE OF THE BRAIN
}

\author{
BY \\ SYDNEY SUNDERLAND \\ Department of Anatomy and Histology, University of Melbourne
}

(RECEIVED JUNE 10, 1948)

\begin{abstract}
A knowledge of neurovascular relations and anomalies at the base of the brain is of importance both for an understanding of certain obscure cranial nerve palsies accompanying diseased vascular states or expanding intracranial lesions, and for an appreciation of cranial nerve topography for the purposes of intracranial surgery. The object of this paper is to direct attention to some normal anatomical features which appear to have been neglected and to record certain anomalous arrangements of a highly practical character which have not hitherto been described.
\end{abstract}

The observations are based on an examination of the brains of 210 dissecting-room subjects in which the anatomical relations at the base of the brain were studied during and following their removal from the cranial cavity. An advantage of this material was that all the brains were hardened in situ, so that the configuration of the parts was preserved.

Clinical records of the cases examined were unfortunately rarely available so that it was not possible to correlate the anatomical findings with any ante-mortem symptomatology where signs of nerve compression might have been expected. The author is aware that this considerably limits the scope of the present study, since in themselves the observations advance no conclusive evidence that the neurovascular relations of the type here described were, or are, responsible for nerve palsies. There is, on the contrary, abundant evidence that nerves may be grossly stretched, compressed, and deformed without the development of any signs or symptoms of disordered function. All that is claimed is that these observations demonstrate that, even when the normal arrangement obtains, large arteries are on occasion so related to nerves that they may press upon, displace, and deform them. In this way they could conceivably impair their function. This possibility is further increased by the presence in some cases of certain anomalous arrangements, and in others, where the vessels are the subject of atheromatous changes or are abnormally large, tortuous, or pulsating. There is already a voluminous literature relating to the association between intracranial aneurysms and the signs and symptoms of nerve compression (Peacock, 1876 ; Beadles, 1907 ; Fearnsides, 1916 ; Symonds, 1923 ; Jefferson, 1937 ; Dandy, 1944 ; and others). The present report, however, is not concerned with the excursions and possible effects of such arterial lesions.

\section{Observations \\ The Optic Nerve}

The internal carotid, ophthalmic, and anterior cerebral arteries are in contact with the optic nerve between the optic chiasma and the optic foramen.

On perforating the roof of the cavernous sinus between the anterior and middle clinoid processes the internal carotid artery is applied against the infero-lateral surface of the optic nerve. The artery then winds outwards beneath the nerve to reach the angle at the lateral extremity of the chiasma between the diverging optic nerve and optic tract, where it gives its terminal branches. The artery is thus directly applied to the inferolateral and lateral aspects of the optic nerve at its chiasmal extremity.

Below the nerve the carotid artery gives the ophthalmic branch, which runs to the optic foramen infero-lateral to and in contact with the nerve. The anterior cerebral artery arises in the angle referred to and passes medially above the nerve to reach the longitudinal fissure. The optic nerve is thus directed laterally between, and may be compressed by, the anterior cerebral artery above and the internal carotid artery below.

These vessels are all favourably disposed to exert direct pressure on the optic nerve, and when this occurs the quadrants first involved will be determined by the neurovascular relations. The vessel 
usually responsible is the internal carotid artery: In Fig. 1 is shown a specimen in which an atheromatous right internal carotid artery compressed the optic nerve and the adjacent surface of the brain while following an unusually tortuous course after its departure from the cavernous sinus.

Partial optic atrophy caused by the pressure of an atheromatous internal carotid or opthalmic artery has been described on several occasions (Elliot Smith, 1905 ; Fuchs, 1924 ; Traquair, 1938).

\section{The OCULOMOTOR NeRVE;}

On emerging from the medial sulcus of the cerebral peduncle, the oculomotor nerve is directed forwards and outwards across the interval outlined by the midbrain posteriorly, the dorsum sellæ anteriorly, and the free margin of the tentorium laterally. The nerve skirts the lateral margin of the posterior clinoid process, which it occasionally grooves, and then passes on to the dural roof of the cavernous sinus along which it continues for some distance before finally penetrating the dura and reaching the lateral wall of the sinus. The site of entry into the dura is usually midway between the anterior and posterior clinoid processes. The nerve consequently runs an exposed course not only while crossing the hiatus of the tentorium but also on the dural roof of the sinus, against the firm surface of which it may be compressed.

At the brain stem the nerve is wedged in the angle outlined between the posterior cerebral and superior cerebellar arteries where these emerge from the terminal portion of the basilar artery. The former branch is directed outwards and slightly upwards over the nerve and above the free margin of the tentorium, while the latter continues laterally beneath the nerve and the tentorium. The angle outlined by these diverging vessels varies in degree, but occasionally it is so narrow that the nerve is constricted where it passes between them. When the basilar artery divides at a lower level than usual the posterior cerebral artery is directed more steeply upwards and outwards in order to clear the free margin of the tentorium, and, in crossing the nerve, may drag on it (Fig. 2). Windle (1888) reported a specimen in which a branch of the posterior cerebral artery pierced the nerve.

Between the posterior and anterior clinoid processes the nerve is closely related to the internal carotid artery. The nerve first crosses the vessel while coursing forwards and outwards across the dural roof of the sinus, which separates it from the artery, and then reaches the lateral wall of the sinus in which, now lateral to the artery, it continues forward to enter the superior orbital fissure. If its entry into the sinus wall is delayed the nerve may be compressed against the roof by the artery as the latter leaves the sinus and turns backwards and outwards to reach the angle between the optic nerve and tract. Involvement of the oculomotor nerve in aneurysmal swellings of the sinus portion of the artery is well known.

The posterior communicating artery usually courses medial to the nerve as it runs between the internal carotid and posterior cerebral arteries. When this vessel is enlarged and replaces the posterior cerebral it is often situated further laterally and so may come to overlie the oculomotor nerve, which is then interposed between it and the firm dural roof of the sinus. Fig. 3 illustrates the grooving of the nerve consequent on such an arrangement. Fig. 4 is of another specimen in which both the internal carotid and posterior cerebral arteries were resting on, and compressing, the nerve before its entry into the sinus wall.

The calibre of the arteries forming the circle of Willis was measured in a hundred specimens. The measurements revealed that the posterior cerebral artery took origin predominantly or entirely from the internal carotid artery on both sides in 6 per cent., and on the right and on the left in 13 per cent ${ }^{-}$ of the specimens respectively (Table I). The corresponding figures of Windle (1888), De Vriese (1904), Fawcett and Blachford (1906), Blackburin (1907), and Stopford (1915) are included fo purposes of comparison.

TABLE I

CALIBRE OF ARTERIES FORMING THE CIRCLE OF WILLIS

\begin{tabular}{|c|c|c|c|}
\hline & \begin{tabular}{|c} 
Both \\
Sides \\
$\%$
\end{tabular} & $\underset{\%}{\text { Right }}$ & $\begin{array}{l}\text { Left } \\
\%\end{array}$ \\
\hline $\begin{array}{lll}\text { Windle (1888) } & . . & \ldots \\
\text { De Vriese (1904) } & . . \\
\text { Fawcett and Blachford (1906).. } \\
\text { Blackburn (1907) } & \ldots & \ldots \\
\text { Stopford (1915) } & . & \\
\text { Sunderland (this } & \text { investigation) }\end{array}$ & $\begin{array}{r}\frac{2}{7} \\
10 \\
2 \\
6\end{array}$ & $\begin{array}{r}5 \\
20 \\
1 \\
7 \\
5 \\
13\end{array}$ & $\begin{array}{r}4 \\
8 \\
1 \\
5 \\
3 \\
13\end{array}$ \\
\hline
\end{tabular}

An atheromatous and markedly curved basilar artery arched upwards and to the right in two specimens to reach the under surface of the oculomotor nerve, which it elevated and displaced laterally (Fig. 5).

\section{The Trochlear Nerve}

Though the trochlear is a thin nerve and runs a long course from the tegmentum of the midbrain to the cavernous sinus, it is nevertheless well protected throughout the greater part of its course by the free margin of the tentorium, beneath which 
it runs as far as its entry into the sinus (Fig. 6). It is thereby shielded from the posterior cerebral artery and the associated supratentorial structures. Inferiorly, however, the nerve is interposed between the tentorium and the superior cerebellar artery. Though the nerve is directed between the posterior cerebral and superior cerebellar arteries, it cannot be constricted between them since, in contradistinction to the arrangement in the case of the oculomotor nerve, the firm tentorium is interposed between them. An aneurysm on the superior cerebellar artery could, however, compress the nerve against the tentorium.

\section{The Trigeminal Nerve}

The relations of the trigeminal nerve and its three divisions in the lateral wall of the cavernous sinus to the internal carotid artery are too well known to require description.

Attention is directed to a vein, which was almost invariably present, which passed from the inner end of the great horizontal fissure of the cerebellum to the inner end of the superior petrosal sinus immediately lateral to the trigeminal nerve.

Usually a small transverse pontine branch of the basilar artery runs laterally beneath the root of the nerve at the pons. This vessel was never so large as to indent the nerve, though its position should be noted in surgical procedures on the nerve root. Stopford (1915) and Watt and McKillop (1935) have described this branch.

As the superior cerebellar artery passes to the cerebellum it frequently loops downwards to the upper surface of the trigeminal nerve. The vessel may indent the nerve (Fig. 7, two specimens) or perforate it (Fig. 8, one specimen).

In three specimens (right 2 , left 1) the posterior inferior cerebellar artery reached, and grooved, the under surface of the nerve root after looping upwards ventral to the pons, the facial and auditory nerves, and the anterior inferior cerebellar artery (Fig. 9).

In two specimens an abnormally elongated and curved basilar artery arched to the left to reach and compress the inner margin of the sensory root (Fig. 10).

The most interesting and unusual of the anomalous arrangements observed affecting this nerve and also the abducent (see later) was one in which a large anastomotic channel ran from the basilar artery to join the internal carotid artery in the cavernous sinus. The first specimen observed formed the subject of a report in 1941 (Sunderland) since which time two additional specimens have been examined - making a total of three in 210 specimens. The arrangement in two of the specimens is illustrated in Figs. 11 and 12 : the one description-suffices for all three. The anastomotic channel, which was left-sided in each case, left the basilar artery at the level of the trigeminal nerve roots and coursed laterally, dorsal to the abducent nerve, till it reached a position posterior to the upper margin of the apex of the petrous temporal and immediately medial to the sensory root of the trigeminal nerve. In two specimens the vessel then accompanied the nerve through the trigeminal foramen into Meckel's Cave, while in the third the artery entered the cavernous sinus through a separate foramen to reach the carotid artery.

Where the nerve and the artery crossed the apex of the petrous temporal together the latter was in direct contact with, and slightly grooved, the flattened upper surface of the sensory root over its inner aspect. In Meckel's Cave the vessel arched downwards, internal to the Gasserian ganglion, turned medially, pierced the inner dural wall of the Cave, and entered the cavernous sinus. It then joined the lateral aspect of the internal carotid artery just after that vessel had entered the sinus.

The anastomotic channel was, in each specimen, the largest branch of the basilar artery and twice the diameter of the posterior cerebral arteries. In all three specimens the remaining branches of the basilar and the formation and branches of the Circle of Willis were normal in size' and arrangement. In one specimen both vertebral arteries were threadlike, and in the other two the vertebral on the side of the anomaly was considerably reduced in size. The anastomotic channel presumably functioned as a compensatory mechanism for the reduced size of the vertebral arteries.

Anomalous anastomoses between the internal carotid and basilar arteries have been reported by Quain (1844), Tüngel (1860), Duret (two, 1874), Tareniecki (1880), Flesch (1882), Hochstetter (two, 1885), Decker (1886), Batujeff (1889), Elliot Smith (1909), and Oertel (1922). In Batujeff's case the basilar artery took origin from the left carotid artery at the base of the skull and entered the posterior cranial fossa through the anterior condyloid foramen. In the other cases the aberrant vessel branched from the internal carotid artery in the cavernous sinus and passed posteriorly either through (Quain, Tüngel, Tareniecki, Hochstetter (two), Oertel) or around (Duret (two), Flesch, Decker, Elliot Smith), the dorsum sellæ to reach the basilar artery. The condition was present on the right side in the cases described by. Hochstetter (one), Tareniecki, Tüngel, Duret (two), and Oertel, and on the left in the remainder. In the cases described by Elliot Smith, Decker, and Flesch the anastomotic vessel, while in the cavernous sinus, 
was related to the Gasserian ganglion and its branches. Their cases, however, differed from those described here in that the vessel skirted the lateral margin of the dorsum sella to enter the posterior cranial fossa, and did not bear the same intimate relationship to the sensory root of the trigeminal nerve.

Such anastomoses are probably established in the following manner. In the embryo many small anastomotic channels linking the internal carotid and vertebral arterial systems develop at the base of the brain and subsequently transfer their origin from the internal carotids to the basilar arterythe latter having been outlined previously by the fusion of the cranial extremities of the vertebral vessels. As a relic of this embryonic relationship, it is not unusual to see the posterior cerebral artery taking origin from the internal carotid after that vessel has emerged from the cavernous sinus. The anomaly under discussion represents the persistence of one of the early anastomotic channels which are usually absorbed as development proceeds.

This vascular anomaly owes its importance to the close relationship which the anastomosing vessel bears to the sensory root and Gasserian ganglion of the trigeminal nerve-a relationship so intimate as to leave an impression on the nerve root. Dandy (1939) believes that pressure on the sensory root by a branch of the basilar artery is responsible, in the majority of cases, for the pain in tic douloureux. - In two of these cases there was evidence that the vessel had exerted pressure on the nerve root, and this pressure, moreover, must certainly have been greatly increased by the pulsations occurring in a vessel of the size present. An investigation of the past history in one case revealed no record of any disturbance of trigeminal nerve function. Case records were not available for the other two.

\section{The Abducent Nerve}

The abducent nerve passes upwards, forwards and slightly outwards from the ponto-medullary junction, just lateral to the mid-line, to the wall of the inferior petrosal sinus. It enters and accompanies the latter beneath the petro-clinoid ligament to the cavernous sinus, along which it continues to the superior orbital fissure.

The nerve is related at the brain stem to the anterior inferior cerebellar, basilar and vertebral arteries and in the sinus to the internal carotid artery.

Anterior Inferior Cerebellar Artery.-The relations of the anterior inferior cerebellar artery to the nerve are summarized in Table II. The artery was anterior to the nerve on the right in 84 per cent. and on the left in 73 per cent. of the specimens. These figures closely parallel those of Stopford (1915), who reported figures of 86 per cent. and 81 per cent. respectively.

In three specimens, all on the left side, this vessel passed through the nerve (Fig. 10). This anomaly has been reported by Valenti (1 specimen), Cushing (3 specimens, 1911) and Stopford (2 specimens, 1915) and in each case it was on the left side. Watt and McKillop (1935) described an artery posterior to the nerves in 40 per cent. and one anterior in 78 per cent. of the sixty specimens examined by them.

On sixteen occasions in the present series the artery deeply grooved the nerve on crossing ventral to it. The past histories were traced in six of these cases and from them it seemed certain that no squint or diplopia had been present during life.

In 1910 Cushing advanced the view that obscure abducent palsies accompanying expanding intracranial lesions could, in certain cases, be explained on the basis of a strangulation of these nerves by the anterior inferior cerebellar arteries. This view was supported by a mass of carefully collected and analysed data in which he showed "(1) that the? arteries, contrary to the usual anatomical description, generally overlie the nerves; (2) that in $a_{\stackrel{\mathbb{Q}}{\mathrm{Q}}}$ series of brains of tumour cases the vessels which normally encircle the brain stem often produce a more or less deep grooving of the nervous tissues (3) that the abducentes in many of these cases are deeply constricted and (4) that a large percentage of the clinical histories of cases which show postmortem pontine grooving, with accompanying implication of the nerves, record either subjective diplopia or the actual presence of a convergent squint observed during life." In conclusion he emphasized the need for an investigation of a larger series of brains than the pathological ones he had examined in order to confirm the neurovascular relations observed by him.

The results of the present investigation and those reported by Stopford (1915) amply confirm Cushing's observations. Stopford, however, believed that "when the artery lies in the dorsal position, the abducent nerve may be compressed against the basi-sphenoid by the vessel, as the former structure proceeds towards the cavernous sinus." My observations support Cushing's contention that the nerve is compressed when the artery is running anterior, and not posterior to it. There is some evidence, however, to suggest that this grooving is not uncommon and is not necessarily associated with signs and symptoms of disordered conduction in the nerve.

Collier (1904) had previously attributed these 

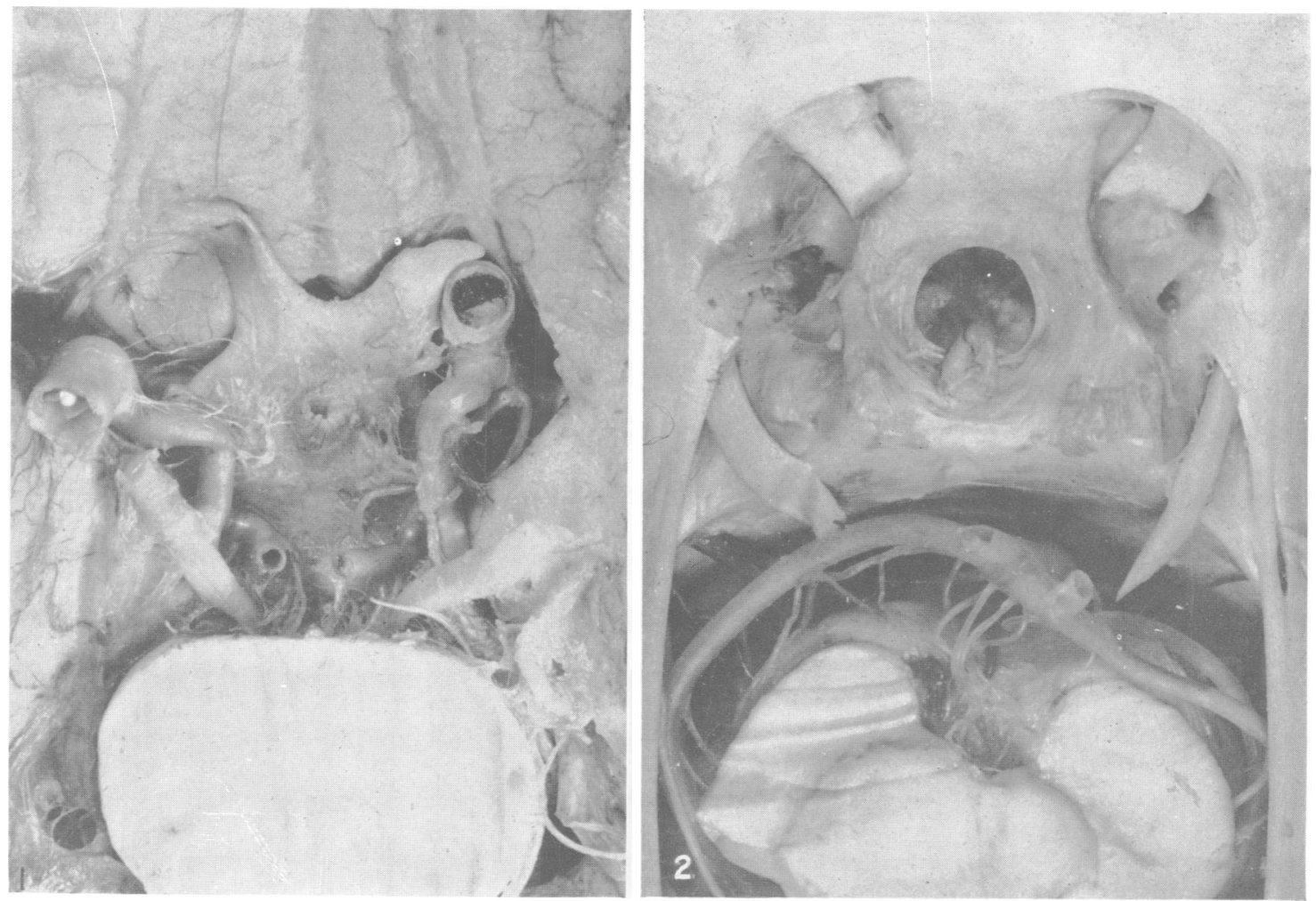

FIG. 1.-Chiasmal region of the base of the brain, showing the right internal carotid artery compressing the right optic nerve and the adjacent surface of the brain.

FIG. 2.-The base of the skull in the region about the pituitary fossa, the cavernous sinus, and the interval between the brain stem and dorsum sellæ (from above). The posterior cerebral artery has been removed on the left side, exposing a deep groove extending into the upper surface of the third nerve. The groove was caused by the artery as it crossed and dragged on the nerve.

FIG. 3.-The base of the skull in the region about the pituitary fossa and cavernous sinus (from above). The left posterior cerebral artery, which branched from the internal carotid artery, has been removed thereby revealing the groove outlined by it on the upper surface of the oculomotor nerve.

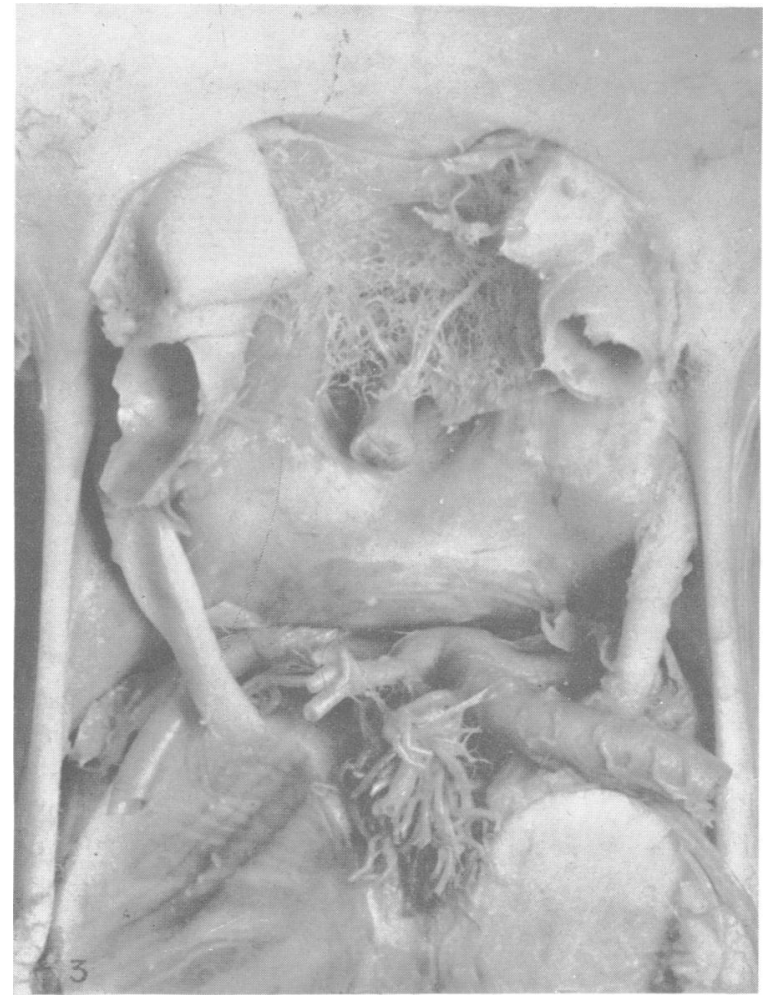



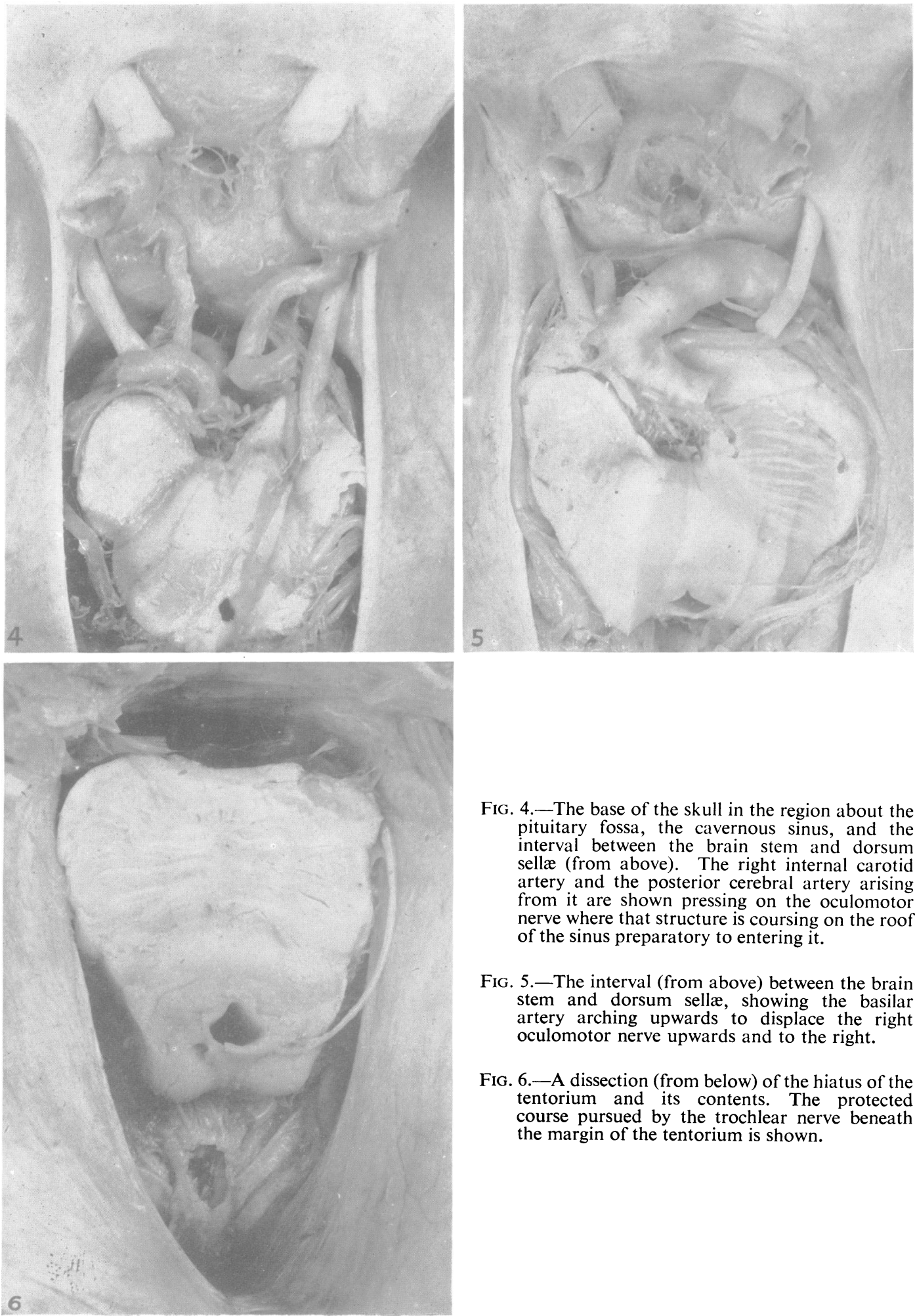

Fig. 4.-The base of the skull in the region about the pituitary fossa, the cavernous sinus, and the interval between the brain stem and dorsum sellæ (from above). The right internal carotid artery and the posterior cerebral artery arising from it are shown pressing on the oculomotor nerve where that structure is coursing on the roof of the sinus preparatory to entering it.

Fig. 5.-The interval (from above) between the brain stem and dorsum sellæ, showing the basilar artery arching upwards to displace the right oculomotor nerve upwards and to the right.

FIG. 6.-A dissection (from below) of the hiatus of the tentorium and its contents. The protected course pursued by the trochlear nerve beneath the margin of the tentorium is shown. 

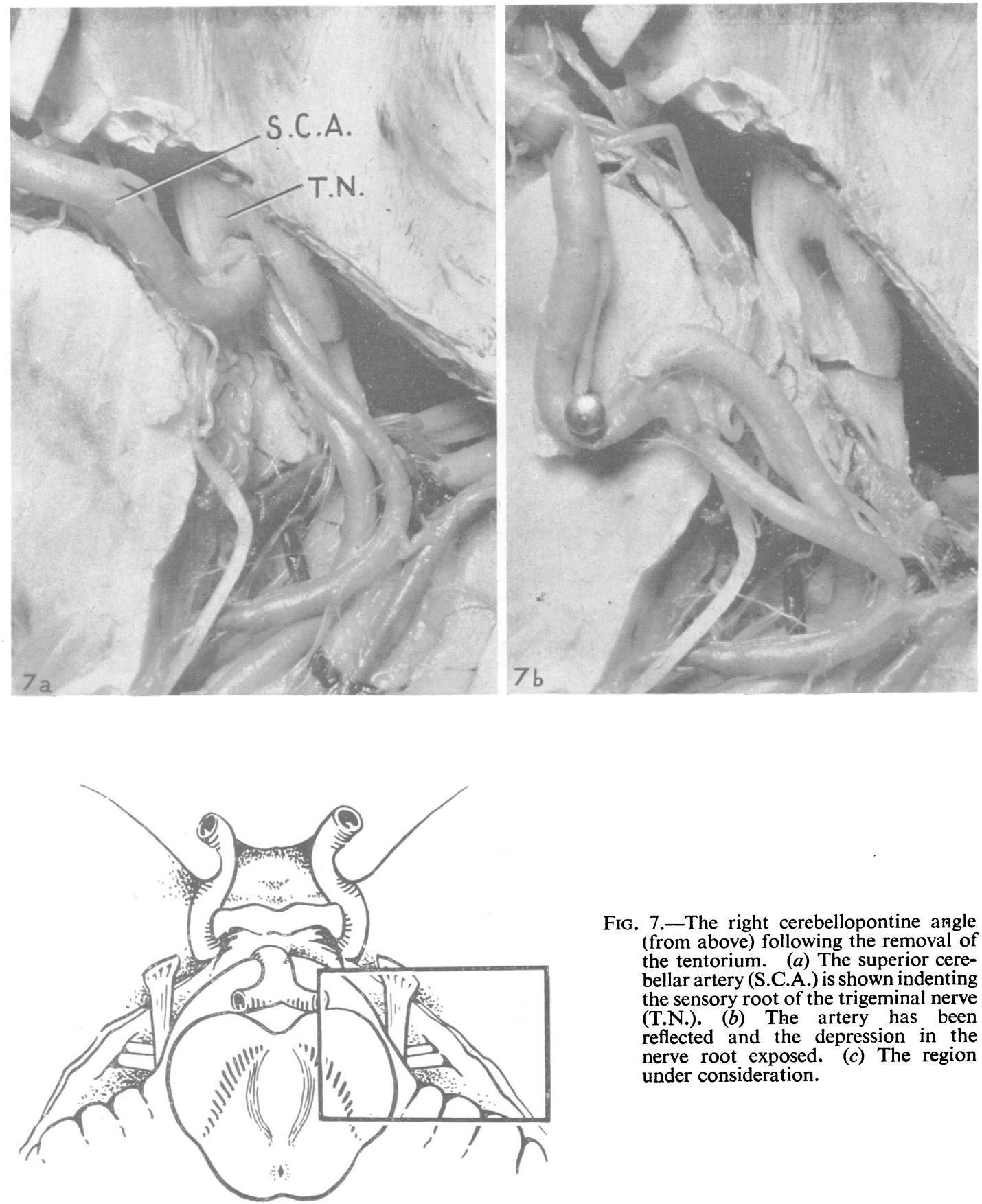

FIG. 7.-The right cerebellopontine angle (from above) following the removal of the tentorium. (a) The superior cerebellar artery (S.C.A.) is shown indenting the sensory root of the trigeminal nerve (T.N.). (b) The artery has been reflected and the depression in the nerve root exposed. (c) The region under consideration.

Fig.7c 

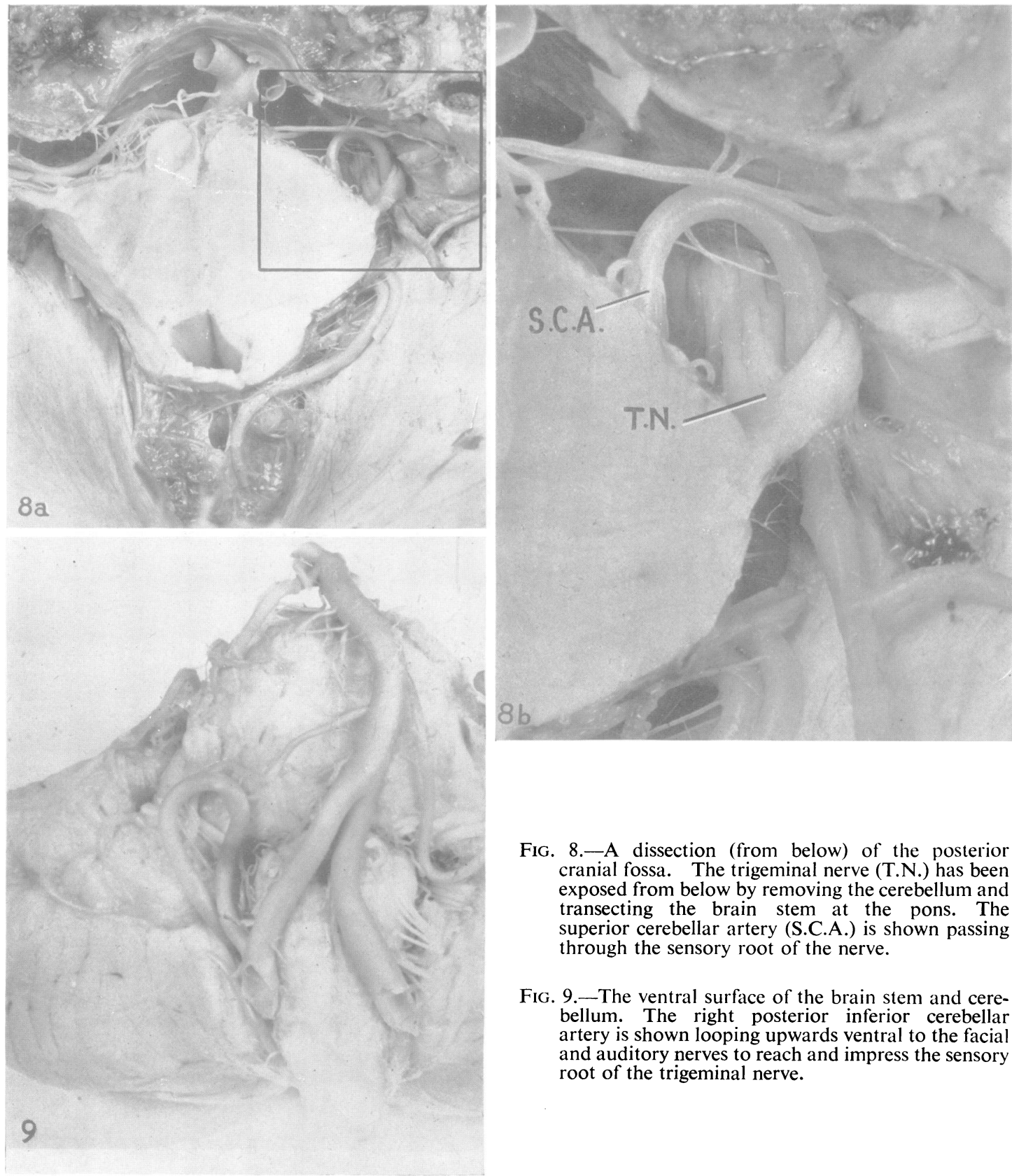

FIG. 8.-A dissection (from below) of the posterior cranial fossa. The trigeminal nerve (T.N.) has been exposed from below by removing the cerebellum and transecting the brain stem at the pons. The superior cerebellar artery (S.C.A.) is shown passing through the sensory root of the nerve.

FIG. 9.-The ventral surface of the brain stem and cerebellum. The right posterior inferior cerebellar artery is shown looping upwards ventral to the facial and auditory nerves to reach and impress the sensory root of the trigeminal nerve. 

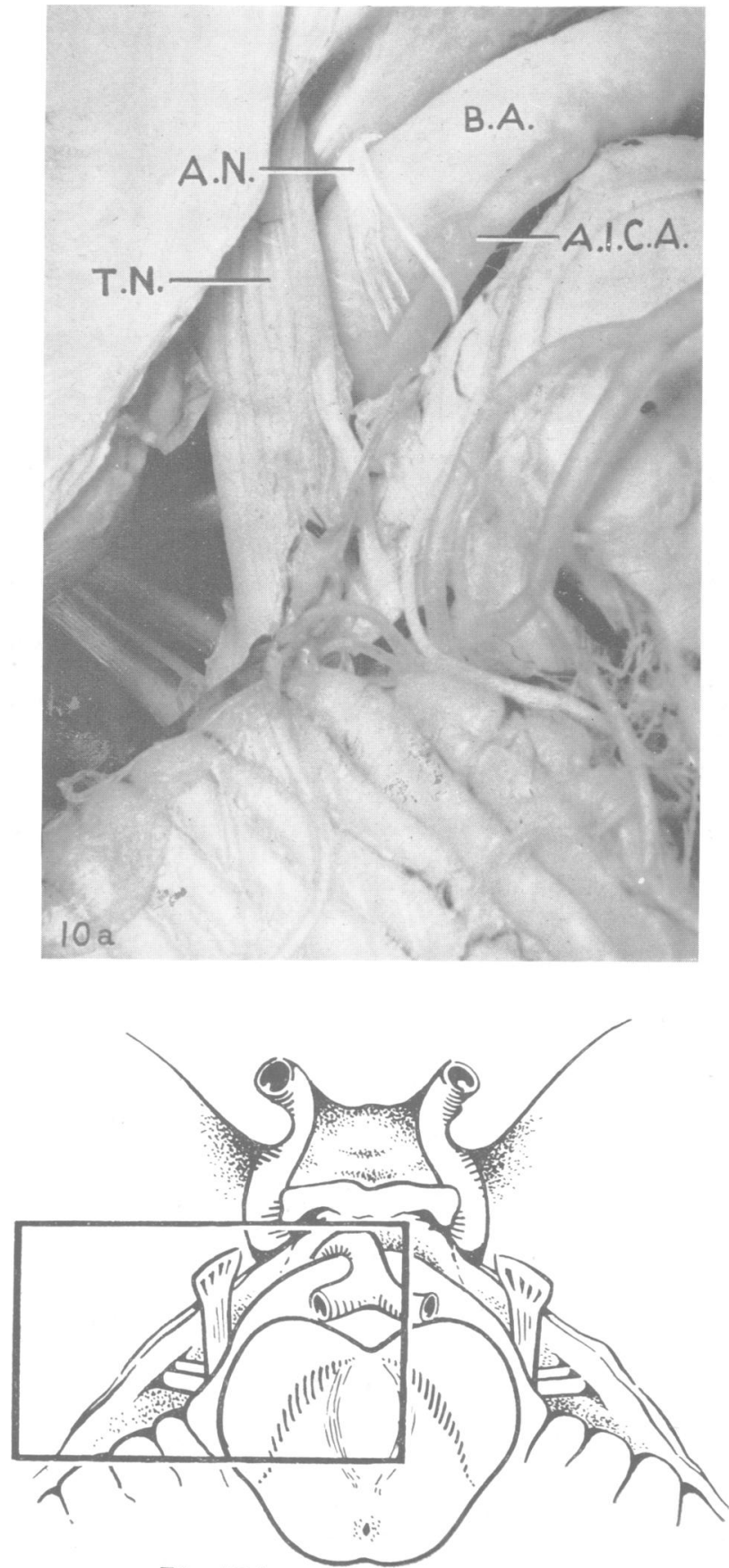

Fig. $10 \mathrm{~b}$
FIG. 10.-(a) The left cerebellopontine angle (from above) following the removal of the tentorium. The trigeminal nerve (T.N.) is shown coursing forwards from the pons to the trigeminal foramen. The basilar artery (B.A.) is shown arching upwards and to the left and impinging on the under surface of the nerve root. The abducent nerve (A.N.) is also shown curving over the vessel while the anterior inferior cerebellar artery (A.I.C.A.), which has been drawn upwards with the basilar artery, is passing through the abducent nerve. The ventral aspect of the brain stem in this specimen is shown in Fig. 13, in which the arrow is directed to the sixth nerve at the site where it is turning over the basilar artery. (b) The region under consideration. 

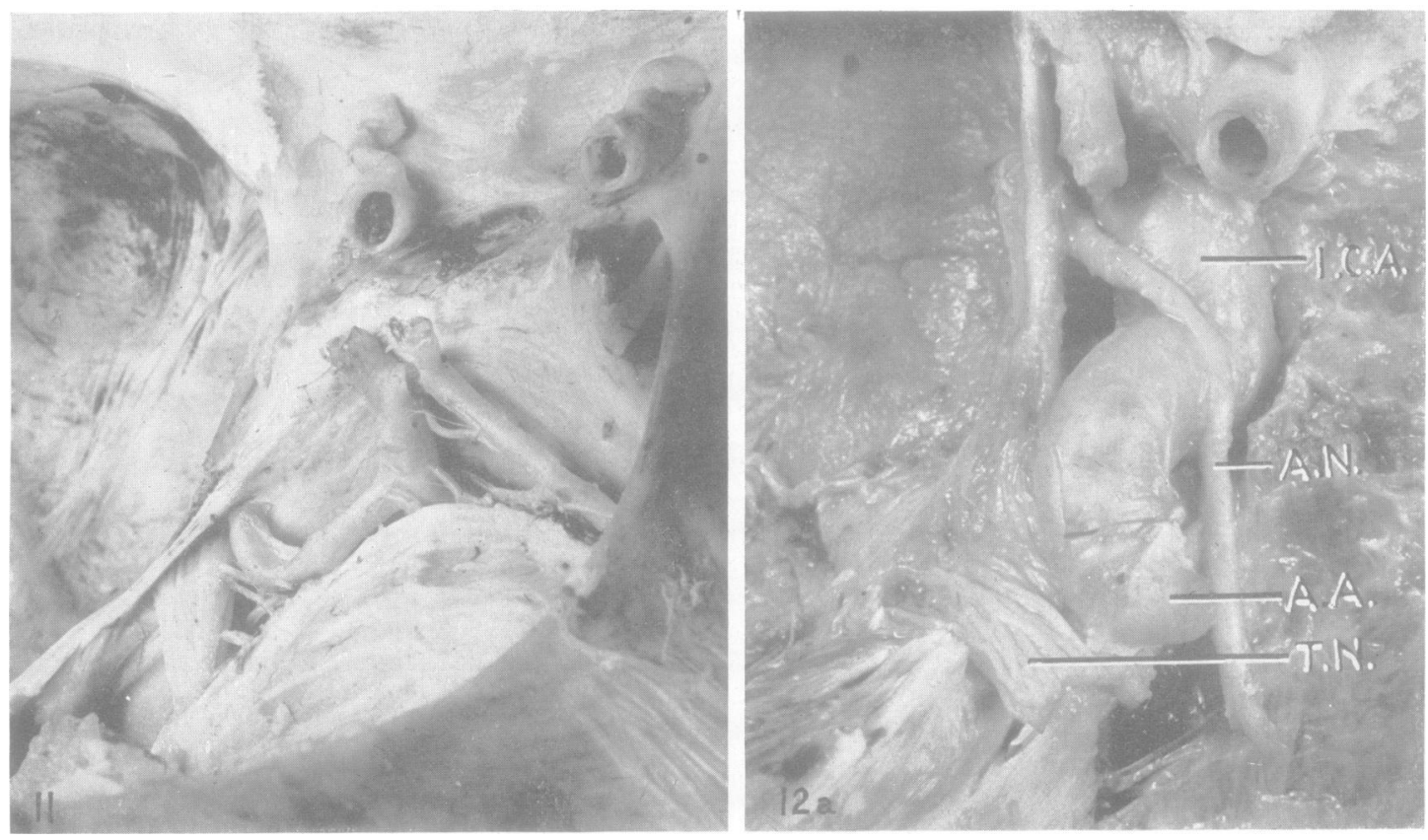

FIG. 11.-Photograph taken through the hiatus tentorii cerebelli, the left margin of which has been divided and displaced, to show the course taken by the anomalous vessel in the posterior cranial fossa. The terminal portion of the basilar artery is seen in the centre of the field and posterior to it the divided surface of the pons, which is partly obscured by the curved right margin of the hiatus. The relationship of the anomalous vessel to the sensory root of the trigeminal nerve, as these structures cross the apex of the petrous temporal to enter Meckel's Cave, is well shown.

Fig. 12.-(a) A dissection (from above) of the contents of the cavernous sinus and the structures related to the upper surface of the apex of the petrous temporal. The sensory root of the trigeminal nerve (T.N.) is shown passing forwards. Immediately to its medial side is the large anastomotic channel (A.A.) from the basilar artery, which can be seen joining the internal carotid artery (I.C.A.) in the cavernous sinus. The abducent nerve (A.N.) is entering the sinus medial to the anastomotic vessel, and when the latter turns down to join the carotid artery the nerve is directed laterally anterior to it. The looping of the internal carotid artery referred to takes the vessel upwards into a position which corresponds to that occupied by the anastomotic channel just after it has entered the sinus. The course of the nerve relative to the loop corresponds with the arrangement illustrated here. (b) The region under con-

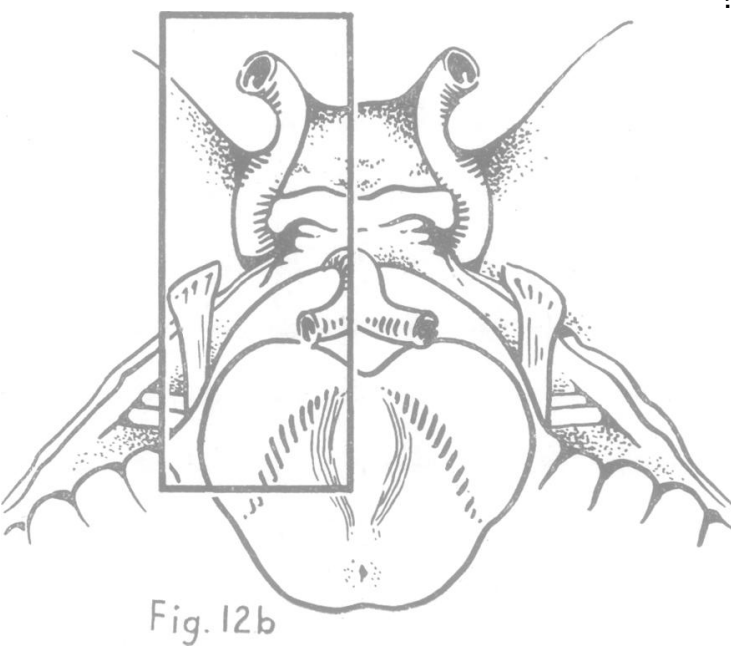



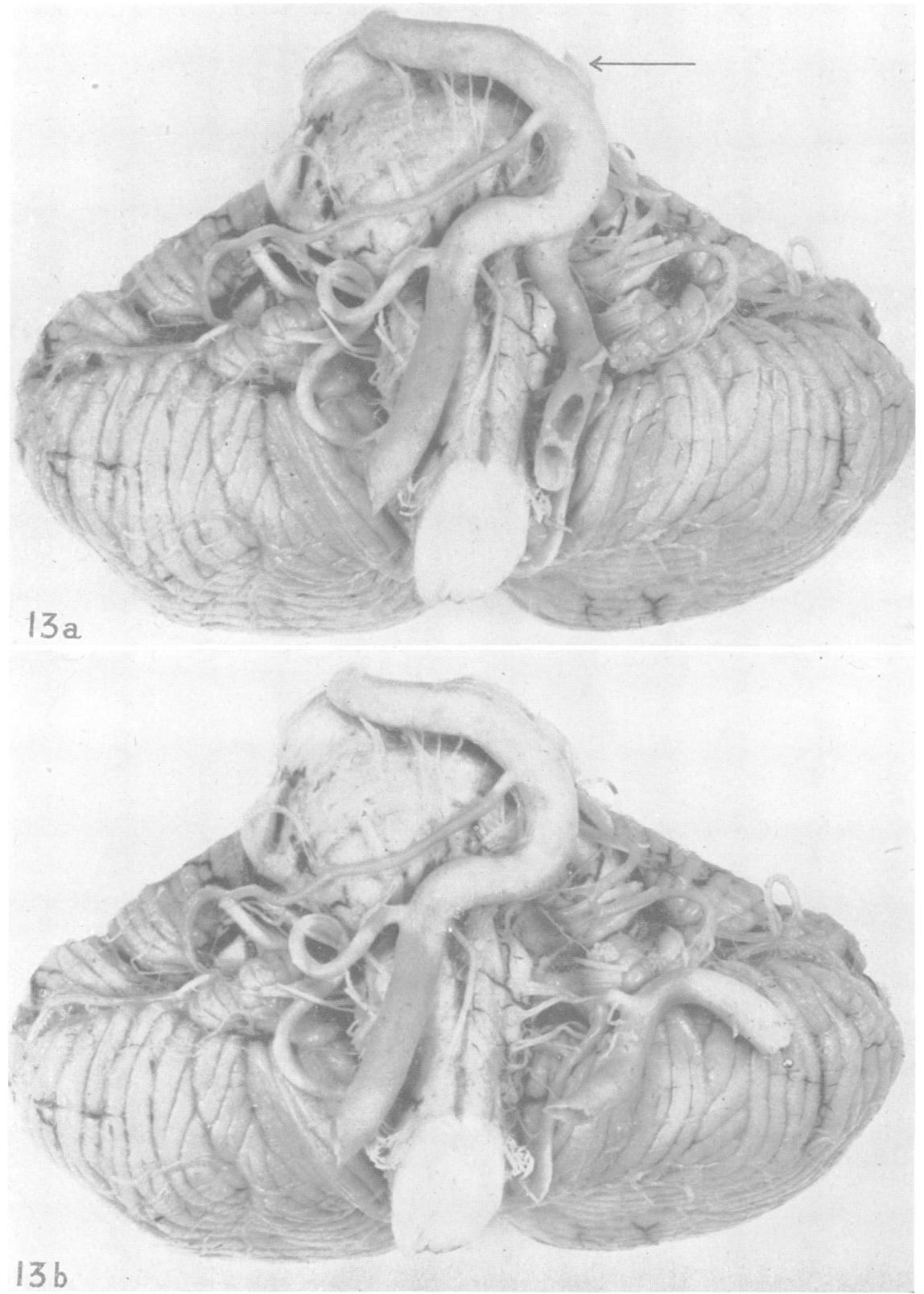

FIG. 13.-Photographs of the ventral aspect of the brain stem and cerebellum showing : (1) the basilar artery arching to the left anterior to the abducent nerve, which can be seen emerging from behind and turning over the artery ; (2) the left vertebral artery arching backwards into the interval between the cerebellum and medulla and compressing the glossopharyngeal, vagus, and accessory rootlets. The depression caused by the artery is shown in Fig. $13 \mathrm{~b}$. 


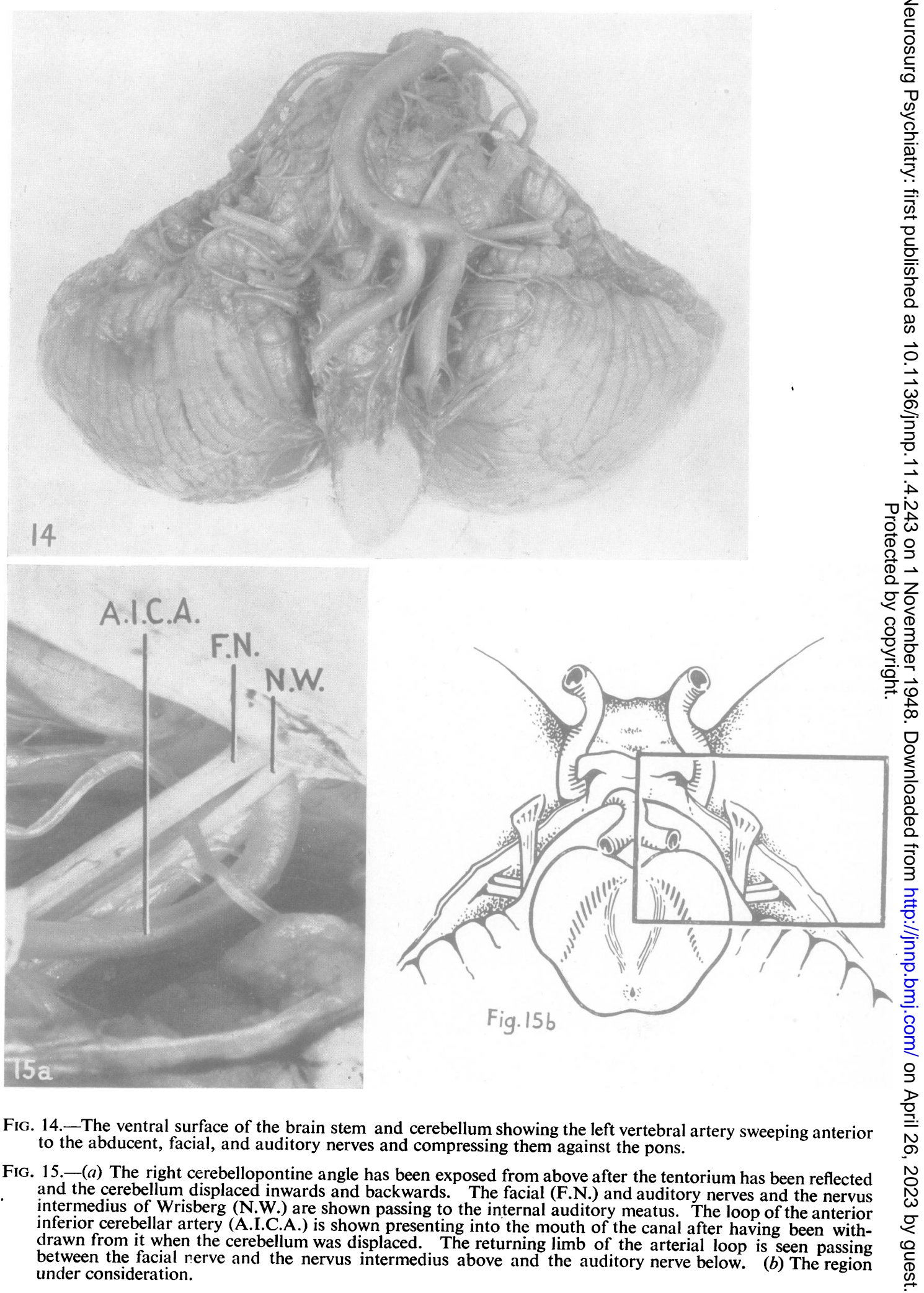


palsies of the abducent nerves to the displacement " backwards" of the brain stem from supratentorial pressure which, in the initial stages, produces traction on the nerves, first on the involved side and then on the other. Wolff (1928) claimed that if this were the factor responsible then the frailer trochlear nerve, with its long antero-posterior course, should be the first nerve affected. However, the direction of the displacement inferred in Collier's description is downwards and not anteroposteriorly as interpreted by Wolff

According to Wolff (1928) the factor responsible for the involvement of this nerve is the bend which it takes over the apex of the petrous temporal as it enters the cavernous sinus, so that the nerve is kinked and constricted at this point when the brain stem is driven downwards. In this connexion it should be noted that the first two points of fixation along the course of the nerve are at the pontomedullary junction and at the site where the nerve pierces the dura in relation to the inferior, petrosal sinus. Consequently, displacement of the brain stem downwards would, in the initial stages, be more likely to stretch the nerve between these two points. The author is convinced, from an anatomical investigation of the disposition of the parts, that Collier's explanation is the more acceptable though in certain cases the neurovascular arrangement, as described by Cushing and confirmed by Stopford and this study, may operate in the manner originally suggested by Cushing.

Internal Auditory Artery.-The internal auditory artery was not significantly related to the abducent nerve in any specimen.

Basilar Artery.-Occasionally (Table III) the basilar artery is deviated to one or other side of the mid-line and comes to overlie directly the abducent nerve, thereby compressing it against the pons. In one specimen the vessel was so curved as to compress both nerves. The greater tendency of the basilar artery to shift or bend to the left (Dandy, 1944) was confirmed in this series.

In four specimens a markèdly curved basilar artery swung to the left and displaced the nerve laterally. In two of these the artery curved so far laterally that it projected beneath the nerve and forced it upwards as high as the upper margin of the pons. The nerve first ascended vertically, compressed against the pons and then turned over the vessel and descended to reach the site where it pierced the dura in relation to the inferior petrosal sinus. The nerve was, in this manner, acutely angulated over the artery between its origin and the point where it entered the dura (Figs. 10 and 13).

Vertebral Arteries.-In approximately 17 per cent. of the specimens one or other or both vertebral arteries curved ventral to, and compressed, the nerve at the ponto-medullary junction (Fig. 14). The arrangement obtaining in these specimens together with the incidence on the two sides is shown in Table III.

Internal Carotid Artery.-The abducent nerve enters the cavernous sinus above the level of the carotid artery as that vessel enters through the floor. The nerve then proceeds along the lateral aspect of the artery and leaves the sinus at the superior orbital fissure. The artery frequently runs a tortuous, rather than a gently curved, course in the sinus and on two occasions, both on the left side, was observed looping acutely upwards immediately on entering the sinus so that the loop ascended lateral to the entering abducent nerve. This necessitated the latter curving abruptly round the front face of the loop in order to reach the lateral aspect of the vessel. The arrangement was similar to that illustrated in Fig. 12.

The Anastomotic Channel between the Internal Carotid and Basilar Arteries.-The anastomotic channel linking the internal carotid and basilar arteries (described above) bore a constant relation to the abducent nerve in the three specimens observed. The nerve entered the cavernous sinus medial to the channel and then, where this vessel turned down to unite with 'the carotid, curved abruptly ventral to it in order to cross the carotid and reach its supero-lateral aspect along which it continued (Fig. 12).

\section{The Facial and Auditory Nerves}

Anterior Inferior Cerebellar Artery.-The anterior inferior cerebellar artery is usually intimately related to the facial and auditory narves at the ponto-medullary junction, in the cerebello-pontine angle, and at or in the internal auditory mzatus. The results of an investigation of the relations of the vessel to these nerves in 132 subjests, with special reference to the internal auditory meatus, have been the subject of an earlier report (Sunderland, 1945).

In 39 per cent. of the specimens the artery passed outwards, anterior to the facial and auditory nerves, to enter the meatus down which it, looped for a variable distance. Before passing to the cerebellum the recurrent limb of the loop then coursed between, above, or below the nerves, either in the meatus or soon after leaving it (Fig. 15).

In 25 per cent. of the specimens the artery just reached the entrance of the meatus into which the apex of the loop projected ventro-medial to the nerves. The distal limb of the loop then passed 
to the cerebellum below or between the'nerves. In several specimens complicated loopings at the entrance to the meatus increàsed the complexity and intimacy of the neurovascular relations at that site.

In 13 per cent. of the specimens the artery did not extend as far laterally as the meatus but passed above ( 1 per cent.), between ( 5 per cent.), or below (7 per cent.) the facial and auditory nerves to reach the cerebellum. In approximately 23 per cent. of the specimens the artery was absent or was not related significantly to the nerves. When the anterior inferior cerebellar artery passed between the nerves it usually did so between the motor division and portio intermedia of the facial nerve.

The intimate relationship of a large arterial channel to the facial and auditory nerves in such a confined space as the internal auditory orifice and canal are anatomical features of considerable practical importance in connexion with surgical exploration of the cerebello-pontine angle and certain disturbances of nerve function which may possibly arise as a direct consequence of mechanical pressure exerted on the nerves by atheromatous, enlarging, abnormally pulsating, or tortuous vessels.

Watt and McKillop (1935) have also directed attention to the passage of the artery over, under, and between the nerves in the cerebello-pontine angle. They concluded that, in effecting this relationship, "the anterior inferior cerebellar artery usually lies close to the surface of the brain " but that "the passage is sometimes made far from the brain surface, close to the mouth of the internal auditory meatus." It is believed that they missed the significance of the relation to the meatus because their observations were made on brains already removed from the cranium. Stibbe (1939) described and illustrated the varying relations of the anterior inferior cerebellar artery to the seventh and eighth nerves in the cerebello-pontine angle but stressed that the most proximal part of the nerve is relatively free from arteries.

Internal Auditory Artery.-The internal auditory artery arose from the basilar artery in 17 per cent. of the specimens (Stopford, 36 and 28 per cent. on the right and left sides respectively; Watt and McKillop, 5 per cent.). In these cases the vessel crossed the cerebello-pontine angle in front of or above the nerves, although usually situated some distance from them. The artery maintained this relative position as it passed along the meatus where the neurovascular relationship was a more intimate one than in the cerebello-pontine angle.

In the remaining 83 per cent. of the specimens the vessel took origin from either the apex or the proximal limb of the first arterial loop formed by the anterior inferior cerebellar artery. The intimacy of the neurovascular relationship was consequently determined by the disposition of the anterior inferior cerebellar artery in the cerebello-pontine angle or in the meatus and by the site of origin of the internal auditory artery from that channel. In general the branch coursed in front of or above the nerves and was more intimately related to them in the meatus than in the cerebello-pontine angle.

Posterior-Inferior Cerebellar Artery.-The posterior-inferior cerebellar artery frequently loops upwards ventral to the facial and auditory nerves at their site of origin, where it may compress them backwards against the pons or the middle cerebellar peduncle (Fig. 9).

TABLE II

RELATIONSHIP OF THE ANTERIOR-INFERIOR CEREBELLAR ARTERIES TO THE ABDUCENT NERVES

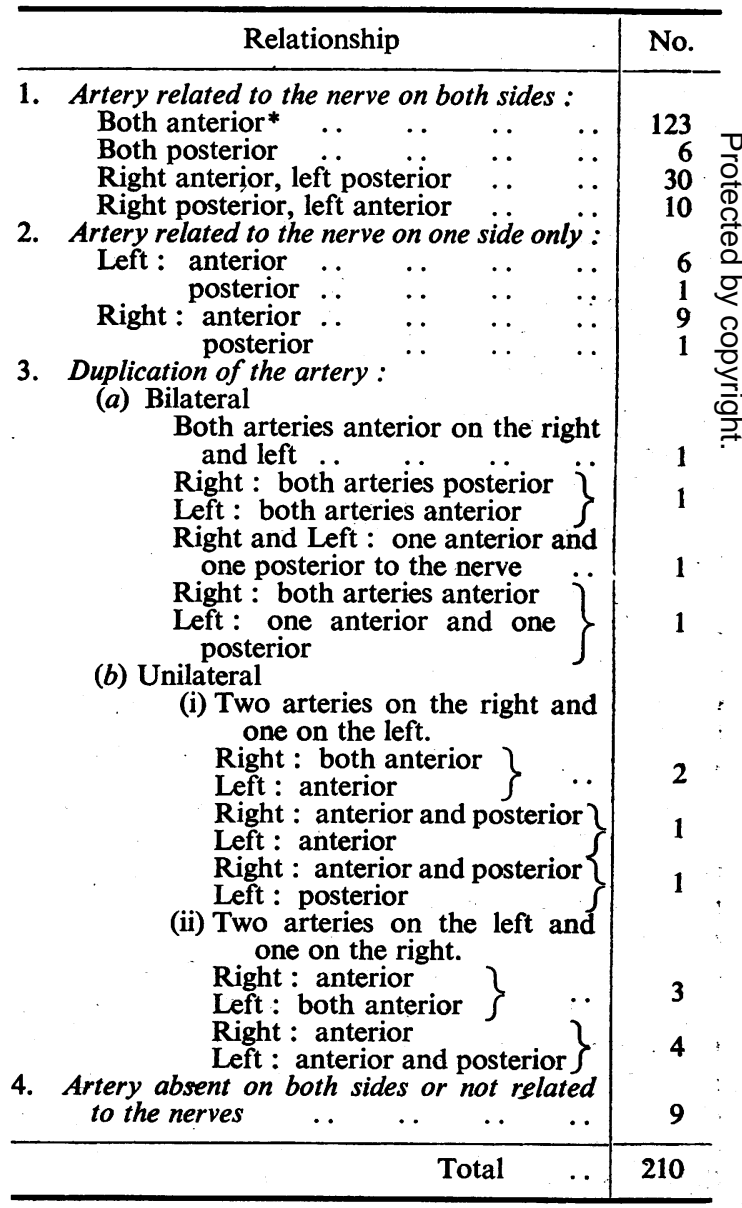

* In three of these specimens the artery pierced the nerve on the left side. 
Basilar and Vertebral Arteries.-Deviation of the basilar artery from the mid-line occasionally takes this vessel not only anterior to the abducent nerve but into contact with the facial and auditory nerves. Dandy (1944) has also observed that "the lateral bend in the basilar artery may come to rest either upon the trigeminal or auditory nerve."

A tortuous vertebral artery may deform the ponto-medullary junction at the site of origin of these nerves and in this way compress them (Figs. 13 and 14). Such a condition was observed in this series on 7 occasions on the right side and 20 on the left.

\section{The Glossopharyngeal, Vagus, Accessory, AND HyPOGLOSSAL NERVES}

The glossopharyngeal, vagus, accessory, and hypoglossal nerves are related to the vertebral and posterior inferior cerebellar arteries in the interval between the medulla medially and the jugular and hypoglossal foramina laterally.

Vertebral Arteries. - Thickened atheromatous vertebral arteries were observed arching forcibly backwards into the interval outlined between the olive medially and the flocculus laterally. The vessel thereby forced the glossopharyngeal, vagus, accessory, and hypoglossal nerve rootlets acutely backwards and compressed them against the medulla as they passed round the artery on their way to their respective foramina. The deformation thereby produced was considerable (Fig. 13). This

TABLE III

RELATIONSHIP OF THE VERTEBRAL AND BASILAR ARTERIES TO THE ABDUCENT NERVES

\begin{tabular}{|c|c|c|c|c|}
\hline \multicolumn{4}{|c|}{ Relationship } & No. \\
\hline 1. & Basilar Artery : & & & \\
\hline & Anterior to the right nerve & . & .. & 3 \\
\hline & $\begin{array}{l}\text { Anterior to the left nerve } \\
\text { Anterior to both nerves }\end{array}$ & - & & 6 \\
\hline \multirow[t]{6}{*}{2.} & Vertebral Artery: & & & \\
\hline & Right vertebral artery & & & \\
\hline & $\begin{array}{l}\text { Anterior to the right nerve } \\
\text { Anterior to the left nerve }\end{array}$ & & & 11 \\
\hline & Left vertebral artery & & & \\
\hline & $\begin{array}{l}\text { Anterior to the left nerve } \\
\text { Both vertebral arteries }\end{array}$ & . & & 21 \\
\hline & Anterior to the right nerve & .. & . & 1 \\
\hline \multirow{4}{*}{3.} & $\begin{array}{l}\text { Basilar and Vertebral Arteries: } \\
\text { Anterior to the left nerve }\end{array}$ & & & \\
\hline & Basilar and both vertebral ar & rteries & . & 1 \\
\hline & Basilar and right vertebral ar & irteries & & . 1 \\
\hline & & Total & & 46 \\
\hline
\end{tabular}

condition was present in this series on the right side in seven specimens and on the left side in twenty.

Posterior-Inferior Cerebellar Arteries. - Each posterior-inferior cerebellar artery follows a variable and very tortuous course, with complicated loopings, as it runs dorsally between the emerging glossopharyngeal, vagus, accessory, and hypoglossal nerve rootlets to reach the interval between the restiform body and the cerebellum. Though the artery is variably related to the emerging rootlets as it courses dorsally, the relationship is always an intimate one and is frequently of such a character as to lead to the deformation and stretching of the nerve rootlets.

\section{REFERENCES}

Batujeff, N. (1889). Anat. Anz., 4, 282.

Beadles, C. F. (1907). Brain, 30, 285.

Blackburn, I. W. (1907). J. Comp. Neurol., 17, 493.

Collier, J. (1904). Brain, 27, 490.

Cushing, H. (1911). Ibid, 33, 204.

Dandy, W. E. (1939). J. internat. Coll. Surg., 2, 5.

-(1944). "Intra-cranial Arterial Aneurysms." Comstock Publishing Co., New York.

Decker, F. (1886). Quoted by Oertel.

De Vriese, B. (1904). Anat. Anz., 25, Suppt. 88.

Duret, H. (1874). Arch. Physiol. norm. Pathol., 6, 60, second series. Quoted by Oertel.

Fawcett, E., and Blachford, J. V. (1906). J. Anat. Physiol., 40, 63.

Fearnsides, E. G. (1916). Brain, 39, 224

Flesch, M. (1882). Quoted by Oertel.

Fuchs, E. (1924). "Textbook of Ophthalmology." Eighth Edit. J. B. Lippincott Co., Philadelphia. p. 100.

Hochstetter, F. (1885). Quoted by Oertel.

Jefferson, G. (1937). Brain, 60, 444.

Oertel (1922). Anat. Anz., Supplement to Vol. 55, p. 281.

Peacock, T. B. (1876). St. Thomas's Hosp. Rep., 7, 119 and 317.

Quain, R. (1844). " The Anatomy of the Arteries of the Human Body." London. p. 507.

Smith, G. Elliot (1905). Rev. Neurol. Psychiat., 3, 182. - (1909). J. Anat. Physiol., 43, 310.

Stibbe, E. P. (1939). Lancet, 1, 859.

Stopford, J. S. B. (1915). J. Anat. Physiol., 50, 131.

Sunderland, S. (1941). Aust. N.Z. J. Surg., 11, 140.

(1945). Brain, 68, 23.

Symonds, C. P. (1923). Guy's Hosp. Reps., 73, 139.

Tareniecki (1880). Quoted by Oertel.

Traquair, H. M. (1938). " An Introduction to Clinical Perimetry." Henry Kimpton, London.

Tüngel (1860). Quoted by Oertel.

Valenti. Quoted in Poirier P. and Charpy, A. :

"Traité d'Anatomie Humaine." Masson et Cie, Paris.

Watt, J. C., and McKillop, A. N. (1935). Arch. Surg. 30, 336.

Windle, B. C. A. (1888). J. Anat. Physiol., 22, 289.

Wolff, E. (1928). Brit. J. Ophthalmol., 12, 22.

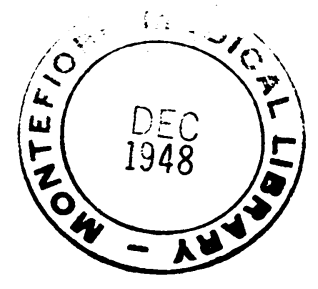

